This is a pre-copy-editing, author-produced PDF of an article accepted for publication in "Journal of Design History" following peer review.

The definitive publisher-authenticated version:

\title{
Ulm Aesthetics
}

\author{
Author: Matthew Holt
}

May 2020, Pages 140-157,

The article is available online at:

https://doi.org/10.1093/idh/epz038 


\section{Ulm Aesthetics}

In order to contribute to the widening and enriching of the notion of aesthetics as it applies to design and so to the historian's task in this field, this essay examines the theories of aesthetics promulgated at the Hochschule für Gestaltung at Ulm (1953-1968), still a much-understudied institution. In particular it will investigate the confluence at that school of semiotics and semantics, information aesthetics, and experimental aesthetics. It looks at the break Ulm made with its predecessor, the Bauhaus, on the role of art and aesthetics in design. That break is seen as result of the HfG's re-evaluation of the profile and substance of industrial design, a re-evaluation itself contingent on an updated understanding of the contemporary 'environment' (Umwelt). The paper also examines the key aesthetic theories of the figures who passed through Ulm and shaped its curriculum in order to establish the influence of those figures on the wider history of design.

Keywords: aesthetics—Bauhaus— environment — Hochschule für Gestaltung Ulminformation theory-semantics

\section{Introduction}

The Hochschule für Gestaltung at Ulm (HfG) became a hub, however briefly, in the post-War era for new principles of design aesthetics that were semiotic, scientific and profoundly influenced by the then embryonic information theory revolution. As the school developed, it moved further and further away from what it perceived to be the expressionist and Romantic vestiges of its predecessor, the Bauhaus. For those directing, teaching, and developing curriculum at Ulm — among them Otl Aicher, Max Bense, Gui Bonsiepe, William S. Huff, Martin Krampen, Klaus Krippendorff, Tomás Maldonado, Abraham Moles, Horst Rittel, and Claude Schnaidt, inter alia - aesthetics was a measurable and computable element pertaining to every fabricated artefact or ensemble of artefacts; it was not an independent field of knowledge or technique that was then applied to design. Rather, aesthetic principles and aesthetic knowledge were to be derived from industrial culture itself. While aesthetics and aesthetic theory were of course also key to Bauhaus training and design philosophy, what distinguishes its Ulm interpretation was the additional emphasis the latter institution placed on aesthetics as a logical language or system rather than as a species, however distant, of art practice. Indeed, the HfG explicitly dissociated itself from the Bauhaus precisely on the matter of art and therefore 'applied art'. Furthermore, while the institution was self-commissioned to intervene in and shape post-War German industry and society by pursuing a pedagogical vision of 'critical rationalism' 1 in determined contradistinction to the fascism from which it emerged, its members also identified the essential features of a nascent postindustrial society. When Ulm cofounder Otl Aicher reflected that ' $[\mathrm{w}] \mathrm{e}$ were interested in the shaping, the gestaltung, of everyday life and the human environment...' , by everyday life he did not only mean industrial culture but the increasing significance of the new 'Umwelt' of media, information, communication, of signs and signals. This significance, grasped as 'man [sic]machine-systems' ${ }^{3}$, was captured in a broad understanding of the emerging status and role of design as a form of knowledge of the environment (Umweltwissenschaft), and as way of manipulating the environment (Umweltgestaltung). To that end, design, Aicher stressed, was not to borrow '... forms from art', nor slip back into the '... applied art mould' ${ }^{4}$ 
More so than the Bauhaus and the Arts and Crafts movements that predated the HfG then, this stance places the aesthetic ideas of Ulm in a genealogy aligned less with Kant and Romanticism than with the science of sensation and perception originally extolled by Alexander Baumgarten. This is especially true of the empirical and experimental sciences which followed Baumgarten's conception; for example, psychological aesthetics (as in Gustav Theodor Fechner and Wilhelm Wundt), optics and physiology (e.g. Hermann von Helmholtz), and the study of perception and empathy (Einfühlung, e.g. Theodor Lipps). ${ }^{5}$ The HfG, however, stepped even further away from this tradition of physiological and perception-based aesthetics. As the aesthetics of design pursued at Ulm was intended to be non-subjective and antiidealist, Ulm favoured an objective vision of the field more closely aligned to semantics, information theory, and to behavioural and statistical psychology. When psychology and perception theory was taught at Ulm it was therefore linked less to a study of 'feeling' than to patterns of user behaviour, or to an analysis of the configuration of environments. As such, the school viewed aesthetics as a nonsubjective 'language' in which form is an element of a design operation, a calculable phenomenon, not an intuitive, creative act. This step also implied that the designer is no longer an artist but a planner, a coordinator. While there have been recent attempts to restore to design and design aesthetics philosophical or artistic credibility, ${ }^{6}$ a far more thought-provoking task for the historian of design, therefore, is to explore alternative, more complex genealogies of aesthetics that have fed into design practice, pedagogy and theory than that of 'applied art'. Such at least is the assignment the following article sets itself. To that end, we will first look at the manner in which Ulm sought to distinguish itself from the Bauhaus. We will then examine the creation of Ulm's own model of design aesthetics and design education, a model which fused together at least three fields: 1) semiotics and semantics; 2) information aesthetics; and, 3) experimental aesthetics. This fusion can be explained by the HfG's reframing of industrial design to respond to the conditions of contemporary technical civilisation which was carried out in tandem with the school's rethinking of what constituted the new industrial 'environment' (Umwelt). For teachers and students at Ulm, responding to this new environment was at once a pedagogical, commercial and ethical obligation and the aesthetic theories of the HfG must be understood in this context.

\section{Ulm and Bauhaus}

The HfG was founded after the Second World War by the Geschwister-Scholl Foundation in honour of members of the White Rose resistance group, Hans and Sophie Scholl, murdered by the Nazis in 1943. Inge Scholl, the surviving sister of the siblings, together with the Ulm based graphic designer Otl Aicher (they later married), envisaged the HfG to be a democratic, enlightened institution for the postwar era. It was first conceived to teach the liberal arts. But with the involvement of Swiss artist, designer and former Bauhäusler Max Bill, the school became linked more closely to the tradition of industrial schools of art and craft

(Kunstgewerbeschule) in Germany, including the Bauhaus, but now addressing the needs of contemporary 'technical civilisation'.

Indeed, it was precisely on the point of what constitutes contemporary technical civilisation that the 'Ulmers', as they were to be known, began to separate themselves from the Bauhaus philosophy and model of teaching. This was a politically painful process, as the foundation director, Bill, was invested in his position precisely on the reputation of his former work at Ulm's predecessor (Hochschule für Gestaltung was part of the full title of the Bauhaus). Indeed, Walter 
Gropius spoke at the official opening of the school in 1954, and earlier the prospectus claimed the college was a "continuation of the "Bauhaus". ${ }^{8}$ The initial curriculum too followed the Bauhaus model. The four years of study began with a generalist first year of education, the 'Vorkurs'. That year contained much of the art training and aesthetic philosophy of the HfG precursor, and Bauhaus instructors Joseph Albers, Johannes Ittens, Helene Nonné-Schmidt, and Walter Peterhans were present for a while at Ulm teaching into the foundation program. Reading René Spitz's comprehensive political biography of the $\mathrm{HfG}^{9}$ it is difficult to distinguish whether the abandoning of the emphasis on art (Bill wanted studios for painting and sculpture, workshops for jewellery, etc.) was the pretext for moving Bill on, or the reason for his exit.

Whatever the case, it was precisely on the issue of art and aesthetics that Tomás Maldonado, the new co-rector of the HfG after Bill's departure (along with Otl Aicher and product designer Hans Gugelot), decided to fully differentiate the two institutions. In the second edition of Ulm, the school's influential journal, Maldonado traced the history of the relation of art, aesthetics and industrial design from John Ruskin and William Morris through the German Werkbund and Henry van de Velde to the point where there was a shift in the Bauhaus itself from an applied art approach to the 'miracle' of the Bauhaus, the 'rationalist aesthetic of industrial production'. ${ }^{10}$ Nonetheless, this miracle was more of a glimpse of the future rather than an enduring, defining characteristic of Ulm's predecessor. Instead Maldonado claimed that in terms of instruction for industrial design, the primarily artistic training undertaken at the Bauhaus is now radically out of alignment with the two 'fundamental currents of contemporary pedagogy, neo-humanist and progressive'. ${ }^{11}$ Maldonado rhetorically stated, 'although Marianne Brandt's geometric tea-set "Bauhaus 1924" is now considered a museum curiosity, it is asserted that we must regard "Bauhaus 1924" pedagogical ideas as important today'. Pedagogically, the Bauhaus system can be reduced to the "exaltation of expression, intuition, and action, above all of "learning by doing"". ${ }^{12}$ The issue for Maldonado is that this approach is fundamentally artisanal, even anti-theoretical. Instead, to be in the 'nerve centre' of contemporary industrial civilisation demands that theory be embedded in practice, practice embedded in theory. The education for the 'new type of designer' is, therefore, to be grounded in 'scientific operationalism'. Operationalism was a term derived from mathematical biologist and systems theorist Anatol Rapoport. ${ }^{13}$ Maldonado deployed the notion, along with references to planning, to give theoretical support to the departure from the HfG's art-driven curriculum, and so to justify his reformulation of the Vorkurs. ${ }^{14}$

In his 1959 article 'der modellfall ulm, zur problematik hochschule für gestaltung' ${ }^{15}$ in issue six of Form, Max Bill hit back, especially on the matter of converting the Vorkurs from a generalist preliminary year which focussed on the principles of aesthetic training, to one in which the student is immediately introduced into departmental specialisation. Bill believed this shift, in which Maldonado played a significant role, renounced the task the HfG gave itself - to produce designers and designs for contemporary technical, informational society. This is because, Bill argued, once computational machines have replaced the automatic parts of human endeavour and human labour, it is 'aesthetic arguments' and their holistic underpinnings that are needed to properly design (that is, give form to) the environment (gestalten der umwelt ${ }^{16}$ ). Bill backed up this statement with the fundamental Bauhausidee of aesthetic amelioration, quoting Gropius proclaiming the belief that the 'artists' freedom is the antidote (die medizin) to the overmechanisation 
that plagues us'. ${ }^{17}$ No such freedom is now evident in Ulm pedagogy. Bill forcefully and somewhat bitterly concluded that 'ulm today, therefore, represents the technicalised degeneration of a once good idea' ${ }^{18}$

Despite this tendency to frame aesthetics as an intervention into industrial culture to compensate for its distasteful and unhealthy elements, it should be made clear this is by no means a purely artistic approach to design on the part of Bill. Bill always associated beauty with practical intention ('gute form' was Bill's expression), and as Klaus Krippendorff, a student at Ulm between the years from 1956 to 1961, reminds us, it was Bill that set up the culture there that equated aesthetics with 'culture-free mathematical forms'. ${ }^{19}$

Nonetheless, in his retrospective view of the HfG, Otl Aicher was even more pointed than Maldonado about the differences between the Bauhaus model of artist practice and the 'Ulm model'. This is not surprising, considering the fraught relationship he had had with Bill. Aicher acknowledges that some part of the Bauhaus legacy attempted to move beyond the artist-as-designer model, especially under Hannes Meyer's direction, but it ultimately retained a respect for the spiritual element of art that, for Aicher, had no place at all at Ulm. He called this transcendental approach to design aesthetics, 'compensatory aesthetics' ${ }^{20}$ By compensatory, Aicher meant a fundamentally 'cosmetic' approach to design in which design is conceived as beautifying, and thereby 'saving', the excessive elements of industrial culture. For Aicher, the departure from art- from, in effect, aesthetics for aesthetics' sake - in the post-war situation was therefore a moral and political choice. In a formulation that would be completely at home in a text by a Frankfurt school member, he argues that art has been compromised by the 'tricks of traditional culture'. Indeed, art and its supposed eternal values (embodied in the Bauhaus by its unswerving faith in the platonic forms, triangle, square, circle) rests on an outmoded, metaphysical valuation of spirit over world, for example, as articulated by Wassily Kandinsky and the theosophical thread that ran through the Ulm's precursor school. There is no longer room for such dualism: instead 'culture must face reality' ${ }^{21}$

According to Aicher, this sets up a choice. Is design the application of fundamental principles exemplified in the Bauhaus' use of elemental geometry and elemental colour, or does it arise from the particular profile and demands of the task at hand? Is aesthetics applied to, or derived from, industrial culture? While aesthetic categories can be identified, Aicher argues, they do not exist in some 'superordinate' sphere. Instead they form a 'grammar, a syntax of design' and the manner in which that grammar or syntax is deployed is dependent on context. An example he gives is that of type. Bauhaus typography, with its excessive emphasis on perfect basic form to construct lettering, does not comply with the needs and constraints of actual habits of reading and therefore legibility is sacrificed to aesthetic values. ${ }^{22}$

As noted by both Maldonado and Aicher, the seeds of the scientific, neopositivistic, and indeed linguistic, approach to design aesthetics were to be found in the Bauhaus itself, especially in the Meyer era. During that period, for example, there was contact between the Bauhaus school and the Vienna Circle, members of which took a mathematical approach, like logical positivism in England (e.g. Bertrand Russell), to demystifying the truth claims of classical philosophy. Wishing to unite the natural and human sciences by establishing a clear, logical and universal language for all propositional thought which would be later influential on information theory, Vienna Circle members Rudolf Carnap, Herbert Feigl, and Walter Dubslav presented their ideas at the Bauhaus. ${ }^{23}$ More particularly, the political economist and applied psychologist Otto Neurath introduced Bauhaus students to statistical models of visual 
meaning-making based on pictographics. This system would become his international picture language, ISOTYPE (International System of Typographic Picture Education), published in $1936 .{ }^{24}$ Carnap, A.J Ayer and, in particular, Ludwig Wittgenstein, were significant points of theoretical reference for members of the HfG. ${ }^{25}$

In summary, the attempt to differentiate Ulm from the Bauhaus was not exclusively to establish an independent institutional identity, nor simply to spite Max Bill, but a concerted effort to redefine the role of aesthetics in relation to design. It was an attempt to de-spiritualise design aesthetics, a theoretical and practical act that obviously required departure from art training and from the idea of the designer-asartist. Because it was no longer tied to Romantic notions of beauty and the 'healing' powers or supposed transcendence of art, aesthetics at the HfG was not so much a form of reparation or amelioration of the excesses of industry, but, as we are about to explore, part of a positivistic and structural approach to a general grammar of design. Aesthetics was one element of a syntax of the systematic shaping of the industrial surround, part of a language that was intended to transcend the dispute between art and design by virtue of the demands of technical civilisation itself, and therefore beholden to the 'responsible handling of technology'. ${ }^{26}$ To properly engage in this responsibility, Gui Bonsiepe, who both studied and then taught at the school, remarked that Ulm instead 'built a bridge to the sciences', and 'vindicated the world of objects and symbols shaped by industry as a legitimate research area' ${ }^{27}$

\section{The Re-evaluation of Industrial Design}

In order to articulate more clearly the forms of aesthetics the Ulmers advanced as 'legitimate research', in this section I will explore the reconfiguration of product or industrial design at the HfG, particularly Maldonado's contribution to that task. This re-evaluation, which pivots on the question of aesthetics, is key to understanding the HfG's concept of design. To that end, it is worth revisiting Maldonado's foundational statement on the topic in Ulm 2, the second issue of 21 in-house publications that contained critical essays and commentary by leading Faculty members along with descriptions of the school's design and teaching activities. This reconfiguration is in many ways the creation of the famous Ulm Model (Ulmer Modell) of pedagogy - a '... balance between theory and practice, between science and design' ${ }^{28}$

As we have already seen Maldonado's piece was controversial in its determination to separate Ulm instructional principles from its predecessor the Bauhaus. To do so, Maldonado presented an assessment of the contemporary state of industrial design in order to confirm the ultimate irrelevance of Bauhaus training for such a context. Indeed, his task was to knock the aesthetic, artistic focus of industrial design and industrial design theory from its traditional perch. After a long discourse on the role of aesthetics in the history of designing for industry, including the Arts and Crafts movements in Britain and on the Continent, and a discussion of Reyner Banham on the 'popular art' of industrial design and styling, he concludes the aesthetic is no longer the primary concern of the industrial designer. This is because in the near future, Maldonado argues, it will be the consumer not the designer (as auteur, as artist) that will have the greater role in the production cycle. He also claims the process of production itself will significantly change. Formerly the product governed the type and operation of the machine used to develop and create it. Now it is the 'operative behaviour of the machine' that 'will to a certain extent determine the process'. ${ }^{29}$ Maldonado foresees that this 'implies that the designer will, more than ever, have to obey factors foreign to his [sic] own individual field' ${ }^{30}$ The very scale of any and all products will be able to be manipulated - predominately miniaturised- 
but also the product's very function may be altered, re-purposed. Essentially, future design will be 're-design'. Maldonado summarises these shifts by saying that at first the industrial designer was an 'inventor', then an 'artist', and thirdly, today, a 'coordinator'. The role of the last covers the entire design process, including collaboration with a wide array of 'specialists', and a knowledge of customers and consumers. ${ }^{31}$ Given the sheer scale and dimensions of this new terrain of design, and given the emergent importance of industrial automation, for Maldonado the designer can no longer be trained in expression, intuition and fine art, summarised by the Bauhaus credo of 'learning by doing', but will instead be versed in contemporary technical, 'operational' knowledge. ${ }^{32}$ The designer will additionally possess a substantial understanding of economics and planning. The training that sets Ulm apart from other schools and pedagogical precedents calls for a more universal design language. In a text from the Ulm archive of 1956 on the theory and planning behind the new foundational teaching program (Grundlehre), Maldonado is explicit about this: previous design pedagogy was dedicated to educating the senses, teaching practice manually, and liberating the expressive capacity of the individual. Today it should be devoted to both the practice and analysis of visual means, cultural problems, social responsibility and being freed from the 'psychological deformations' of early training. ${ }^{33}$

Maldonado's own contribution to this interdisciplinary project was extensive, and not only theoretical. Among many other activities, it included design of an early symbolic computer language for Olivetti [1], a system-wide reformulation of the La Rinascente brand and business model in Milan begun in his last year at Ulm (both commissions were taken with Bonsiepe ${ }^{34}$ ), and regular teaching appointments at the architecture faculty at Princeton. He also took part in seminars, lectures, working groups and committee work across the globe. Furthermore, a concrete example of the operationalist, synthetic and researched based approach to design knowledge was the formation (albeit short-lived) of the Institute for Visual Perception

(Forschungsinstitut für optische Wahrnehmung), established with the financial backing of the Ford Foundation, and headed by the American Mervyn Perrine, also from Princeton. ${ }^{35}$

It must be said, however, that the exact nature of this new training and multidisciplinary discourse was never completely settled at Ulm and remained a source of constant debate and indeed tension. As noted, Aicher backed the decision to break with Bill and support the reforms organised by Maldonado. But in the early 1960s another fault line opened up in the school, precisely on the relative importance being laid on theory and on practice. While sympathetic to the turn to such fields of research as logic and semantics - the first book he acquired for the HfG library was a volume of Charles Morris' theory of signs ${ }^{36}$ - Aicher was wary of any decontextualisation of syntactical inquiry. 'Where had the message gone?' he asked. ${ }^{37}$ He thus did not support theory that strayed too far from design concerns, and came to side with the studio practitioners over the 'scientists'. By the latter he primarily meant Horst Rittel, who replaced Max Bense in 1958, and taught operations research, mathematics, and cybernetics, and Hanno Kesting, who taught sociology. ${ }^{38}$ This division became the source of a bitter political dispute, involving, moreover, students on both sides of the 'debate'. 39

Nonetheless, there was an attempt made by most Ulmers to capture the multidisciplinary research areas appropriate to a reformulated concept of industrial design under the notion of 'environment'. This concept is much easier to understand in German, where environment is 'Umwelt', the surrounding world in which one is 
immersed and which the designer attempts to 'shape', 'Umweltgestaltung'. The devotion to this concept at Ulm was there from the beginning of the school to its end. ${ }^{40}$ Speaking of the new socio-technical conditions under which HfG pedagogy operated, the 'scientist' Rittel stated, 'we live in [a] highly technological environment, plugged into complex communication networks... at the same time we are actors in the various scenes of our complicated social structure: as consumers, as taxpayers, as purchasers, as voters, etc. ${ }^{41}$ This understanding of the environment as essentially communicative was common across all HfG pedagogy. In particular it was theorised through an ambitious combination of cybernetics, information theory and the biological 'Umwelt-research' of Jakob von Uexküll. Indeed, late in the short history of Ulm, Bonsiepe hoped the legacy of the HfG would be an environmental science of design: 'Design which might claim to organize and leave its imprint on a highly artificial and in future complicated environment (Umwelt) needs the creation of a science of design (Wissenschaft der Gestaltung) as a branch of a future science of environment (Umweltswissenschaft) ${ }^{4}{ }^{42}$ [2] This vision would have a transnational impact, only now beginning to be traced.

\section{Semiotics and Semantics}

The broader, multidisciplinary discourse appropriate to what was effectivelywithout the HfG naming it so-postindustrial design, was to be found in general communication theory. As practiced at Ulm this included semiotics, semantics, cybernetics and information theory. Part of a broader 'linguistic turn' in the social and technical sciences, the HfG was one of the first institutes (if not the first) to fully apply these theories to design pedagogy. But unlike semiology and structuralism as related to design (for example, Roland Barthes, Umberto Eco, and Jean Baudrillard), the emphasis at Ulm was less on the legacy of Ferdinand de Saussure and his syntagmatic understanding of language, nor his dualistic division of the sign (signifier, signified), than on the Americans C. S. Peirce and Charles Morris. The HfG particularly focussed on Morris' division of the semiotic system into pragmatics, semantics and syntactics (Morris, in fact, had a design connection: he was a good friend of Bauhäusler László Moholy-Nagy ${ }^{43}$ ). The pragmatic approaches of Peirce and Morris to signifying activity allowed Ulm teaching to explore a whole range of meaning-making values and processes in analysing the design object and in formulating design methods. In the Visual Communication program, for example, the course on semiotics included the study of 'signs, symbols, signals, emblems'. ${ }^{44}$ Semantics is broader still. In his reformation of the foundation program, Maldonado defined semantics as the '.. the practice and analysis of the meaning of the forms' ${ }^{45}$ a definition which could be seen as a way of purposely rezoning, as it were, Bauhaus concepts. At any rate the two fields naturally intersect, and they were put together, for example, in what Reyner Banham described as Maldonado's 'hard-driving Semantik und Semiotik... "Information Seminar"". ${ }^{46}$ But the distinction was maintained at certain critical moments by Ulm teachers. Klaus Krippendorff would go on to use semantics as an explicit alternative to semiotics in articulating designed phenomena, claiming semiotics is too encumbered with metaphysical distinctions between sign and thing, symbol and reality. ${ }^{47} \mathrm{He}$ clearly has in mind semiology. Whatever the case, the appeal of both fields to the HfG was that they were thought to be objective and scientific in approach, not based in artistic and thereby intuitive or spiritual values. In either semiotics or semantics what is primarily emphasised is the selection and use of a signifying element in order to construct a message from an already established 'language'. The accent, then, is not on the psychological state or subjective perception 
of the speaker (or origin of the message). To this end, and evidenced by the text on the subject Maldonado produced while at Ulm, the HfG's approach to semiotics was fundamentally taxonomic. ${ }^{48}$ Bonsiepe, for his part, exhaustively elaborated upon rhetoric and rhetorical figures in visual communication design. ${ }^{49}$ In his course Anthony Fröshaug asked students to explore representational codes_-grids, lattices, matrices - to comprehend 'concrete problems' (e.g., circulation within a building, a street plan, an underground rail system) [3]. According to Fröshaug, these problems cannot be grasped 'intuitively' nor by a 'feeling for form'. Rather, the process must be methodical, mathematical and 'systematic'. ${ }^{50}$ The emphasis is again placed on nonsubjective, textual and visual semantic (and syntactical) 'rules'.

But what exactly is so encompassing about this broader understanding of language? Maldonado's article 'Communication and Semiotics', based on lecture material and taking up almost the entire content of the Ulm journal's fifth edition of 1959 , provides an answer. The piece situates semiotics as the interdisciplinary theory to unite a vast range of discourses appropriate to the study of design, for the notable reason that the field of communication studies, of information, messages, signs and signals, is common to the seemingly separate domains of human society, animals and machines. Within this framework both artificial and natural languages can be mapped over each other ("“mixed" structures', organic, electronic, mechanic, he says ${ }^{51}$ ). While Maldonado is particularly attentive to the limits of this mapping, forfeiting on the Leibnizian idea a universal calculus can 'remove the conflict of opinions', he does not ascribe the role of a unifying language to the aesthetic; it is, rather, to be sought in the semantic paradigm.

Despite Maldonado's written declarations, aesthetics not based primarily on a 'communicative', linguistic approach still had a role in the pedagogy of Ulm, as evidenced in either Josef Albers' or Maldonado's own version of the Grundkurs. Both owed considerable debt to Gestalt theories of visual perception and maintained formal experimentation (what the Bauhaus called Formlehre). In fact, Walter Zeischegg, who taught into the foundation course, reversed Louis Sullivan's tenet 'form follows function' and claimed function can only arise from what is already available as form-for Zeischegg, functionality was, in fact, 'subordinated form' ${ }^{52}$ Later Maldonado would argue the inseparability of form and function is due to that which unites them, information: ' ...it seems obvious that establishing a relationship between form, function and information has always been the indisputable task of designing (die unbestreitbare Aufgabe des Entwerfens)' ${ }^{53}$ Furthermore, according to Krippendorff, the work of the HfG had a 'hidden' aesthetics of functionalism. He argues this aesthetic conviction fashioned products of great elegance and simplicity concurring with strict mathematical principles (Max Bill's clock, and a street lamp designed by students under Zeischegg are his examples), but no new vision of use itself. That reappraisal, according to Krippendorff at least, can come only from a discussion of 'meanings' rather than through the detailing and perfecting of form. ${ }^{54}$

\section{Information Aesthetics}

While statistical approaches to design form and user responses to those forms were already evident in some Bauhaus syllabi, Ulm fully introduced the then relatively new field of information theory into its curricula. Information theory was based on the work of Claude Shannon and the research into feedback systems (cybernetics) of Norbert Weiner (who visited and lectured at the HfG in $1955^{55}$ ). The physicist and philosopher Max Bense was an early adopter of this theory in Germany, and taught at Ulm from 1954 to 1958 . The philosopher, physicist and social psychologist, Abraham 
Moles, at Ulm from 1961 to 1966, was to take up and explore the same set of theories in France. The core concepts of information theory, including entropy, redundancy, probability, channel capacity, noise, etc., were all applied to both design methods and designed phenomena at Ulm. ${ }^{56}$

The basic principles of Bense's contribution to the HfG were, first, that contemporary technical civilisation demands forms of knowledge and understanding that are beyond the traditional distinction between nature and culture, and within culture itself (as Kultur) beyond the division between low and high culture (or between design and art for that matter). Second, following the inspiration of the American pragmatists and Shannon's information theory, the appropriate mode of present-day knowledge is not culturally specific metaphysics but 'universal' semantics. In that context, and third, Bense differentiates between classical aesthetics and the modern aesthetics of technical civilisation by defining the former as concerned with objects in themselves (the ontic) while the latter is concerned with what is communicated (the semantic). 'In classical aesthetics', he writes, echoing Hegel's nomenclature, 'there is something in and of itself (an und für sich) that is beautiful (schön): the moon, sun, wind, a rose, scent, a feeling (ein Gefühl), etc. In modern aesthetics things only become beautiful through the sign that one finds for them: through the sound, the verse, the image, the metaphor, through arrangements, rhythms, metrics, perspectives' ${ }^{57}$

Thus, Bense's project was to clarify the state and role of post-classical aesthetic knowledge. In the context of Ulm, this meant aesthetic production and experience no longer belonged exclusively to the artist and to the art object, but was a broader phenomenon encapsulating all 'communicative' artefacts (including, for example, advertising: in 1952, Bense published the book, Plakatwelt ${ }^{58}$ ). In his extensive work on aesthetics, he used American mathematician George David Birkhoff's measure of relative order and complexity-the formula $M=O / C$, where $M$ is 'aesthetic measure', $O$ is order, and $C$ complexity - to define aesthetic information. ${ }^{59}$ In information theory, redundancy is order. Less complexity therefore means more order; more complexity, more information. These principles were comfortably applied to designed phenomenon. Too much 'order' and a product would be aesthetically simple and therefore, one presumes, disengaging, dull, or unclear as to its intention; while at the other end of the spectrum would lie the unexpected and overly complicated. This end belongs less to functional items than to the informationally maximal gestures of art, particularly avant-garde art (Bense had a long and committed relation to experimental literature and concrete poetry, collaborating in establishing the journal Augenblick and book series, Rot $^{60}$ ).

At Ulm, Moles was appointed fulltime professor in 1965. He taught 'sociodynamics of culture', cybernetics and system theory, computing and programming. ${ }^{61}$ Moles begins his 1958 book which informed his classes, Théorie de l'information et perception esthétique (appreciably revised by the author himself for the English translation of $1966^{62}$ ), with the acknowledgement that Nineteenth Century science based on matter and energy displaced human presence from its calculations and its worldview; in building a bridge, Moles says, the user of the bridge goes 'unmentioned'. Communication theory returns the individual to the domain of calculable phenomena: the science of the physical world and the science of behaviour are reconnected at the level of the signal (i.e., the triadic structure of sender, message, receiver). Significantly, this reconnection is understood as incorporating not only the natural and behavioural but elements that are collective and broadly historical (Moles' examples include even political economy). In an article also entitled 'théorie de 
l'information' for the first edition (1968) of the Zagreb based magazine Bit, Moles emphasises this synergy of elements can be understood as 'environmental'. Consciously using Jakob von Uexküll's terminology, he says that to 'perceive the world is to establish a dialogue between man [sic] and Umwelt', but that surrounding world, Umwelt, is now thoroughly social and communicative; it is composed of messages. We are 'immersed' (immergé) in mass media, and therefore the scientific distinction between the observer and the observed no longer holds. ${ }^{63}$

For information theory a message is defined as a 'sequence of elements drawn from a repertoire' ${ }^{64}$ According to Moles, every message has two such repertoires and 'rules of organization', the semantic and the aesthetic.

Semantic information is essentially a blueprint for action. Moles gives the examples of a 'military order, an electrical circuitry diagram, a coded message, instructions in case of a fire, a technical manual, a musical score', etc. ${ }^{65}$ Semantic information is 'logical' and utilitarian. It constituted by standard, systemised code(s). Insofar as semantic information is composed of potentially universal rules it is translatable to other languages, and 'commutable', Moles emphasises, into other channels: the same magnitude of information can be conveyed to a receptor in various media.

Aesthetic information, on the other hand, does not have as its goal the preparation of action. In fact, Moles argues, it has no 'goal properly speaking', ${ }^{66}$ While he is careful not to restrict aesthetic information to works of art only, he claims that aesthetic information is 'specific to the channel which transmits it', for example, a 'symphony cannot replace an animated cartoon'. His argument is that this branch of information is, as opposed to semantic information, not readily translatable. This is because the aesthetic message is essentially 'unforeseeable'. ${ }^{67}$

It is difficult, nonetheless, to see the qualitative difference Moles proposes between semantic and aesthetic information as anything but a reinvention at the level of information theory of the difference between the utilitarian, purposive artifact (in this case, the purposive 'message' or the symbol), and that of the work of art that is characterised by a fundamental autonomy in regards to 'goal', and therefore a presumption of untranslatability between channels or media. In terms of information theory itself there is no technical reason why complexity should be associated with art forms per se, while other prosaic phenomena contain higher redundancy: it is a semantic scale, as it were, not differentiation at the ontic level.

Whatever the case, in Ulm 6, 1962, Moles applies this relative value of complexity much more convincingly to design. In that issue he claims that our 'environment... appears to the cybernetician as an immense assembly of organisms', ${ }^{68}$ and true to the cybernetic vision, that assembly is composed of mind and matter, animals and machines, and that the whole operates at a qualitatively different level than the sum of the individual parts. For 'machines', or assemblies of objects (and sub-objects), there are two dimensions: the structural (the composition of the assemblage), and the teleological (the use or goal of the assemblage). Together they form a system that is 'complex' or composite (zusammengesetzt). ${ }^{69}$ Machines communicate, and are part of the communicative composite, and therefore can be studied and explained by information theory. We can thus determine whether specific designs have (or should have) relative and various degrees of structural complexity and functional complexity. An Enzo Mari designed puzzle (1957) has, according to Moles, a low degree of functional complexity and a relatively high degree of structural complexity; and, apparently, the IBM 705 is the "highest degree of functional and structural complexity yet achieved by man [sic]'. ${ }^{70}$ Moles in fact 
provides a graph to determine these relative levels, with functional complexity forming the y-axis and structural complexity the x-axis. ${ }^{71}$ The images Moles provides for his examples are fascinating in their own right, insofar as he generally chooses objects displaying their inner working with the shell or exterior removed (as in the IBM example, an Underwood typewriter without its case, or the inside of a Braun television set). This reverses to some extent the platitude of design only affording agreeable, pleasant skins for complex objects. Nonetheless, that year Ulm students designed a new body for an Austin Healey Gran Turismo.

\section{Experimental aesthetics}

As we have seen, the Bauhaus had begun to explore the combination of psychology, perception theory and aesthetics, especially under Hannes Meyer. At Ulm this was extended to include information theory and statistical approaches to form, but also new theories beyond Gestaltism of visual communication and perception. Maldonado, Fröshaug, the American William S. Huff, and Martin Krampen inter alia, were all involved in the research and development of new types of aesthetic and perceptual knowledge. This form of experimental aesthetics took at least two, interrelated forms: first, research into visual 'structuring', which was quickly aligned with an emerging understanding of the reach and destiny of computing, and second, more behavioural in scope, research into stimulus-response theory (also in the context of the humanmachine relation). Huff in particular worked on symmetry and topology, 'to design', he argued, ' $i$ s first of all to structure', ${ }^{72}$ while Krampen, initially exploring semiotics in an urban and architectural context, ${ }^{73}$ developed an extensive program of visual study and social psychology after Ulm when he moved to Canada in the mid-1960s. To explicate, here I will focus on Krampen.

Acknowledging its origins in experimental psychology and in particular the patronage of that field established by Gustav Fechner's Vorschule der Aesthetik (1876), Krampen, both a student and then teacher at Ulm, came to define experimental aesthetics not exclusively as a set of artistic exercises or laws encompassing colour, shape, geometry, texture, etc., but instead from a situational point of view (Fechner's aesthetics 'from below'74), and explored whether responses to aesthetic phenomena could be measured empirically. If a good deal of aesthetic perception and therefore design efficiency and success lies in the receiver's behaviour, then the study of an experimental approach to aesthetics will shift emphasis away from the 'ego-defense' mechanisms of the designer, and 'improve and speed-up ${ }^{75}$ the design process itself. This approach to design aesthetics emphasises the receiver, the audience, rather than the author.

In taking this approach, Krampen charts a fine line between the kinds of market research methods most Ulmers disparaged ${ }^{76}$ and a user- or receiver-centric approach to design and designing. Nonetheless, consistent with Ulm teaching, aesthetics for Krampen is primarily defined as communication (in this case, between 'artist' and audience). Therefore, it is also consistent with Bense and Moles' vision of design and information theory, insofar as information theory implicates response into the message's information value, and indeed its logistic potential (the capacity of the channel to carry the message and to be received as intended, that is, with less 'noise').

As aesthetics in Krampen's view is response-based, the artist is essentially a pattern maker; in fact, there are three stages that comprise the 'aesthetic process': the maker of the pattern (the stimulus), the performer, who 'reproduces the patterns of stimulation', and the audience, who, in a somewhat odd turn of phrase, 'secures access' to the stimulus patterns. ${ }^{77}$ Effectively, and not surprisingly, these stages 
reproduce the sender-message-receiver triad at the heart of Claude Shannon's information theory. It also echoes Horst Rittel's game theory, especially in the sender stage, when the designer, no longer ego-driven, nonetheless anticipates 'mentally a competition with other patterns, artistic or non-artistic' ${ }^{78}$ Furthermore, much of the design theory and pedagogical principles common to Gestalt ideas, the Bauhaus and to a lesser extent Ulm itself - 'unity in variety', symmetry, order, complexity, rhythm, novelty, etc. - can be re-inscribed under the conditions of whether a pattern leads to, and Krampen is quoting D. E. Berlyne here, "“arousal" and "attention" '. 79

This is basic, Krampen admits, so he turns to a more complex method of acquiring reception-based statistical evidence from the audience, namely the semantic differential scale developed by Charles S. Osgood, and now used widely-in psychometric testing, for example. ${ }^{80}$ Aesthetic preferences for certain patterns can therefore be mapped and stored to predict the relative success, if not appeal, of a design (and so too if the principle of the design can be easily grasped, or whether it disperses attention). Though psychological and behavioural in nature, and like all statistical approaches entangles the qualitative within quantitative, this form of design aesthetics is, along with all Ulm-inspired aesthetics, an attempt to depart from an artist-driven, Romantic conception of the design process.

\section{Conclusion: Ulm now}

Martin Krampen and fellow Ulmer (and documentary film-maker) Günther Hörmann argued there were three distinct pedagogical 'phases' at the HfG - the Bauhaus phase, the science phase, and the turn to social sciences. ${ }^{81}$ It would be more accurate to say that in the school's brief history there were shifts back and forth between these phases (and the design methodologies and teaching staff identifying with them), and therefore between conventional industrial designing to what we have called 'environmental' designing and planning. The relation of aesthetics to design at Ulm also followed this back-and-forth pattern: however reconfigured, the HfG had a place for Bauhaus style Formlehre and Gestaltism, but it also struck new ground by reorientating (and to some extent dispersing) design aesthetics within contemporary modes of multidisciplinary knowledge. We could also note here an irony regarding we have set forth as Ulm aesthetics: rather than a multiform approach to aesthetics (as might be expected given its plurality of approaches to design), the HfG was notorious for an entirely specific 'aesthetic': clean, minimalist, proto-computational, seemingly without humour or whimsy; all encapsulated by the famous 'right angle' of Ulm, der rechte Winkel ${ }^{82}$ [4] (the only curved shaped at Ulm was apparently the bar in the cafeteria).

Nonetheless, conceptually Ulm pedagogy foreshadowed essential features of the postindustrial nature of contemporary society and economics that were beyond or otherwise than form and objects, if not intangible: planning, systems, communication, information, and above all environmental complexity. The faculty and students at the HfG staked out essential methodological and pedagogical processes to design for these features. As Maldonado and Bonsiepe in particular discerned, that complexity of environment needed an appropriate mode of knowledge to comprehend it and act upon it (Umweltwissenschaft). At this point, perhaps there is reconciliation to be had with the Bauhäusler Max Bill and the 'hard-driving' semantics, semiotics and information theory of Ulm. Perhaps aesthetics understood as the universal logic of interconnections and relations, while not necessarily scientific by nature, is precisely the 'environmental' knowledge field most suited to the contemporary designer. Whatever the case, for the historian of design, the HfG represents, in a fleeting, 
flaring moment, a sketch of the possibilities of multiple visions of design with a vast network of consequences - and an as yet unexhausted investigation of design aesthetics. Ideas of reconciliation aside, while the Bauhaus may still be better known, given its relevance Ulm's time has come.

\section{Caption list}

Fig 1. Tomás Maldonado and Gui Bonsiepe, 'Symbol System for Electronic Data Processing Machine' (1960/61), commissioned by Olivetti, Ulm 8-9, 1963, p. 24, detail. Inv. Nr. AZ 54.45 (C) HfG-Archiv / Museum Ulm

Fig 2. Gui Bonsiepe, 'Environmental Science Diagram', Ulm 21, 1968, p.12 C HfGArchiv / Museum Ulm

Fig 3. Anthony Fröshaug, 'Circulation matrix of a le Corbusier building', in Fröshaug, 'Visual Methodology', Ulm 4, April 1959, p. 63 (C) HfG-Archiv / Museum Ulm

Fig 4. Otl Aicher, 'Tableware and setting for Lufthansa', 1962, Ulm 10/11, 1964 p. 44. The ragged edge of torn bread is the only form not to comply with the Ulm aesthetic. Inv. Nr. 64/0436 C HfG-Archiv / Museum Ulm

${ }^{1}$ G. Bonsiepe, Interface - An Approach to Design, E. Martin (trans.), Jan van Eyck Akademie, Maastricht, 1999, p. 122.

${ }^{2}$ O. Aicher, 'bauhaus and ulm', in H. Lindinger (ed.), Ulm Design: The Morality of Objects. Hochschule für Gestaltung Ulm 1953-1968, D. Britt (trans.), The MIT Press, Cambridge, MA., p. 124. The essay is also collected in a different translation in O. Aicher, the world as design, M. Robinson (trans.), Ernst \& Sohn, Berlin, 1994, pp. 85-93.

${ }^{3}$ T. Maldonado \& G. Bonsiepe, 'Wissenschaft und Gestaltung / Science and Design', Ulm, Quarterly Bulletin for the Hochschule für Gestaltung, 10/11, 1964, p. 28.

Hereafter the HfG journal is referred to as Ulm.

${ }^{4}$ Aicher, op. cit., p. 125.

${ }^{5}$ For an overview of physiological, experimental and psychological/behavioural aesthetics in the 'age of science', see K. E. Gilbert \& H. Kuhn, A History of Aesthetics, $2^{\text {nd }}$ ed., Dover, New York, 1972 (1953), pp. 524-549.

${ }^{6}$ For instance, in 'everyday' aesthetics (Y. Saito, Everyday Aesthetics, Oxford University Press, Oxford, 2007), or the attempt to incorporate the functional and purposeful under the aesthetic categories they have been traditionally excluded from, as in Jane Forsey's The Aesthetics of Design (Oxford University Press, Oxford, 2013). ${ }^{7}$ Ulm 1, 1958, p. 2.

${ }^{8}$ Lindinger (ed.) op. cit., p. 19; p. 129: 'Die Schule ist die Weiterführung des "Bauhaus" (Weimar-Dessau-Berlin)'. For a prehistory of the HfG, see E. Moser, Otl Aicher, Gestalter, Hatje Cantz, Ostfildern, 2012, pp. 105-121.

${ }^{9}$ R. Spitz, HfG Ulm: The View Behind the Foreground: The Political History of the Ulm School of Design, 1953-1968, Edition Axel Menges, Stuttgart, 2002.

${ }^{10} \mathrm{~T}$. Maldonado, 'New Developments in Industry and the Training of the Designer', Ulm 2, 1958, p. 29.

${ }^{11}$ Ibid., p. 38. 
12 Ibid., p. 38, p. 39. See also Maldonado, 'Is the Bauhaus Relevant Today?', Ulm 8/9, 1963, and the exchange of letters with Gropius, Ulm 10/11, 1964. See also interview with Maldonado, Tomás Maldonado in Conversation with/en conversación con María Amalia García, Fundación Cisneros, New York \& Caracas, 2010, pp. 55-63, in which at the age of 88 , Maldonado is more circumspect, describing the HfG as a 'continuation of [the Bauhaus] tradition - but a critical continuation'. Ibid., p. 61.

${ }^{13}$ A. Rapoport, Operational Philosophy. Integrating Knowledge and Action, Harper $\&$ Bros., New York, 1958 (originally published 1953). Not unlike Maldonado, Rapoport was a true interdisciplinary intellectual, a mathematician, biologist, philosopher, psychologist, semanticist, game theorist and concert pianist; his work coalesced in systems science and organisational theory. Rapoport essentially locates his work within the context of the field of 'general semantics'. On that point, there is a further connection at Ulm: among the visiting lecturers (in 1960) was S. I. Hayakawa (Lindinger, op. cit., p. 277; Spitz, op. cit., p. 241) author of the well-read 1949 book Language in Thought and Action that played a significant role in popularising the general semantics of Alfred Korzybski. Hayakawa also became in a Republican senator after a term as president of San Francisco State University in which he was known as a breaker of student demonstrations and faculty strikes. ${ }^{14}$ In his article on Ulm in the IAUS journal, Oppositions, Kenneth Frampton too notes Maldonado's reference to Rapoport, connecting the latter's thinking with John Dewey's 'pragmatic-instrumentalism' and defining operationalism as understood by Rapoport as a 'synthetic action-orientated discipline'. K. Frampton, in Lindinger (ed.), op. cit., pp. 139-140. It should be remembered that the anti-art stance held towards design methodology and curriculum should be taken with grain of salt: Maldonado began his career as an artist and was a central figure in the Argentine chapter of the concrete art movement (for Maldonado's own view of that period, see Tomás Maldonado in Conversation, op. cit., pp. 26-36), indeed Max Bill's association with that movement was one of the reasons Maldonado first visited Europe in the late 1940s, and he was to publish a book on Bill's work in 1955.

${ }^{15}$ M. Bill, 'der modellfall ulm, zur problematik hochschule für gestaltung', Form 6, pp. 18-19; English language version is on pp. 46-47. Bill also designed the cover (and a number of other early Form issues).

${ }^{16}$ A note here on the use of lower caps: it was a Bauhaus phenomenon common to Bill and the Ulm School in general. Aicher made it his signature writing style for his entire career. Horst Rittel called the phenomenon Ulm's 'lower case mania' (Lindinger [ed.], op. cit., p. 118). But the post-war context gave this 'mania' new meaning. As all nouns in German are capitalised, it implied a democratisation of a language seen to be compromised. Nonetheless in the introduction to the collected writings of Bill, Karin Gimmi argues that Bill's adoption of exclusively lower case has more humble origins in streamlining 'office management practices'. M. Bill, Form, Function, Beauty = GESTALT, ed., P. Johnston, intro, K. Gimmi, Architectural Association, London, 2010, p. 15.

${ }^{17}$ Bill, 'der modellfall ulm', op. cit., p. 19; p. 47. This issue also contained a reprint of Walter Gropius' Bauhaus manifesto.

${ }^{18}$ Ibid.

${ }^{19}$ K. Krippendorff, The Semantic Turn, Boca Raton, FL., 2006, p. 313. For a précis of Bill's long-held position, see his 'Schönheit aus Funktion und als Funktion', Das

Werk: Architektur und Kunst, vol. 36, 1939, pp. 272-274. http://doi.org/10.5169/seals28357. Accessed 12/07/2018.

${ }^{20}$ Aicher, world as design, op. cit., p. 191. 
${ }^{21}$ Aicher, in Lindinger (ed.), op. cit., p. 125.

22 Ibid., p. 128. Aicher's own typeface, Rotis, named after the town in Allgäu where Aicher and Inge Scholl moved in 1972 (Lindinger [ed.], p. 270), is not that easy to read either; it is thin and narrow, and carries a particularly difficult lowercase ' $c$ ' in both its serif and sans-serif versions.

${ }^{23}$ M. Droste, Bauhaus 1919-1933, Reform and the Avant-Garde, Taschen, Köln, 2011, p. 70; and see M. Krampen \& G. Hörmann, Die Hochschule für Gestaltung Ulm - Anfange eines Projektes der Unnachgiebigen Moderne/ The Ulm School of DesignBeginnings of a Project of Unyielding Modernity, Ernst \& Sohn, Berlin, 2003, p. 19.

${ }^{24} \mathrm{O}$. Neurath, International Picture Language. The First Rules of Isotype, Kegan

Paul, Trench, Trubner \& Co., London, 1936.

${ }^{25}$ See Maldonado, 'Communication and Semiotics', Ulm 5, 1959, pp. 74-75; and Aicher, 'use as philosophy' in O. Aicher, analogous and digital, M. Robinson (trans), Ernst \& Sohn, Berlin, 1994, p. 107-130.

${ }^{26}$ Ibid., p. 24.

${ }^{27}$ In S. Goll, 'Traces and Hopes of Design Research: An Interview with Gui

Bonsiepe, Klaus Krippendorff, Siegfried Maser, and René Spitz', K. Hunter (trans.), Design Issues, vol. 31, no. 1, Winter 2015, p. 20.

${ }^{28} \mathrm{H}$. Lindinger, 'Ulm: Legend and Living Idea', in Lindinger (ed.), op. cit., pp. 11-12.

${ }^{29}$ Maldonado, 'New Developments in Industry and the Training of the Designer', Ulm 2, 1958, p. 37.

${ }^{30}$ Ibid.

${ }^{31}$ Ibid., p. 34.

32 Indeed, at this point Maldonado cites the work of Kimball and Morse (1951), originally published by the US Navy in 1946 (P. Morse \& G. Kimball, Methods of Operational Research, Dover Publications, Mineola New York, 2003). The authors, particularly Kimball, were to be influential in bringing research originating in a military context to applications in business and industry processes.

${ }^{33}$ T. Maldonado, 'Grundlehre', HfG-Archiv Ulm: Akte Unterricht Grundlehre 2eA298, 1956, reprinted in form + zweck, 20, 2003, pp. 22-27. My summaries from the original German.

${ }^{34}$ On these two projects, see R. Riccini, 'Tomás Maldonado and the Impact of the Hochschule für Gestaltung Ulm in Italy', in G. Lees-Maffei \& K. Fallan (eds), Made in Italy: Rethinking a Century of Italian Design, Bloomsbury, London \& New York, 2014, pp. 89-105.

${ }^{35}$ Ulm 2, 1958, p. 43; see also Spitz, op. cit., p. 221; Krippendorff, op. cit., p. 306.

${ }^{36}$ Aicher, world as design, op. cit., p. 91.

${ }^{37}$ Ibid.

${ }^{38}$ Spitz, op. cit., p. 239 and 259f; Krippendorff, Semantic Turn, op. cit., p. 311: Rittel introduced 'methods of operations research, mathematical decision theory, game theory, systems analysis, and planning techniques'.

${ }^{39}$ See Spitz, op. cit., pp. 259ff; and R. Spitz, "Design is not a Science": Otl Aicher's Constitutional Putsch at the HfG Ulm and His Credo for the Social Responsibility of Designers', Design Issues, vol. 31, no. 1, Winter 2015, pp. 7-17.

${ }^{40}$ In the school's initial planning, '... the Ulm concept needed a focus, everyone agreed on what is now called "Environmental Design"”. H. Jacob, "HfG Ulm: A Personal View of an Experiment in Democracy and Design Education', Journal of Design History, vol. 1, no. 3/4, 1988, pp. 221-234, p. 221.

${ }^{41}$ H. Rittel, in Werk, 8, 1961, cited in Lindinger (ed.), op. cit., p. 94. See also Rittel's material on environment delivered in 1964 at the School of Architecture, University 
of California Berkeley, collected in J-P Protzen \& D. J. Harris, The Universe of Design: Horst Rittel's Theories of Design and Planning, Routledge, London \& New York, 2010, pp. 85-94.

${ }^{42}$ G. Bonsiepe, 'Commentary on the Situation of the HfG', Ulm 21, 1968, p. 12.

${ }^{43}$ See R. Posner, 'Charles Morris and the Behaviourial Foundations of Semiotics', in M. Krampen, et. al. (eds), Classics of Semiotics, New York \& London, Plenum Press, 1987, p. 23.

${ }^{44}$ Ulm 1, 1958, p. 21.

${ }^{45}$ Maldonado, 'Grundlehre', op. cit., p. 26. My translation.

${ }^{46}$ R. Banham, 'HfG Ulm in Retrospect', in Lindinger (ed.), op. cit., p. 59.

${ }^{47}$ See Krippendorff, op. cit., pp. 273-279, and M. Holt, 'Semiotics and design:

Towards an aesthetics of the artificial', The Design Journal, 20:sup1, 2017, S332-

S341, DOI: 10.1080/14606925.2017.1352860

${ }^{48}$ T. Maldonado, Beiträge zur Terminologie der Semiotik, Ebner, Ulm, 1961, and see Krippendorff, op. cit., p. 306.

${ }^{49}$ G. Bonsiepe, 'Visual/verbal Rhetoric', Ulm 14/15/16, 1965, pp. 23-40.

${ }^{50}$ A. Fröshaug, 'Visual Methodology', Ulm 4, 1959, pp. 57-68. The Englishman Fröshaug originally studied graphic design but also science before coming to Ulm (later he would study architecture). He took part in designing for the exhibitions Britain Can Make It (1946), Festival of Britain (1951), and Purpose and Pleasure (1952); see Lindinger (ed.), op. cit., p. 271.

${ }^{51}$ T. Maldonado, 'Communication and Semiotics', Ulm 5, 1959, p. 7.

52 C. Leopold, 'Precise Experiments: Relations Between Mathematics, Philosophy and Design at Ulm School of Design', Nexus Network Journal, vol. 15, no. 2, 2013, p. 373. DOI 10.1007/s00004-013-0148-6. Accessed 12 January 2018.

${ }^{53}$ T. Maldonado, '«Design», Gestaltung, Entwurf-neue Inhalte’, in T. Maldonado, Digitale Welt und Gestaltung, G. Bonsiepe (hrg.), Birkhäuser, Basel, 2007, pp. 365374, p. 369. My translation.

${ }^{54}$ Krippendorff, op. cit., p. 317. For an overview of Krippendorff's experience at the HfG, see his 'Designing in Ulm and off Ulm', in K.-A. Czemper (ed.), HfG, Ulm; Die Abteilung Produktgestaltung; 39 Rückblicke, Dortmund, Verlag Dorothea Rohn, 2008, pp. 55-72. Retrieved from http://repository.upenn.edu/asc_papers/138 $16 / 07 / 2018$

${ }^{55}$ See Ulm, 10/11, 1964, p. 12.

${ }^{56}$ For an overview of Bense and Moles' work in terms of information theory, see F. Nake, 'Information Aesthetics: An [sic] Heroic Experiment', Journal of Mathematics and the Arts, vol. 6, nos. 2-3, June-Sept., 2012, pp. 65-75.

${ }^{57}$ M. Bense, Ästhetische Information, Aesthetica II, Agis-Verlag, Krefeld, 1956, p. 30. My translation.

${ }^{58}$ M. Bense, Plakatwelt, Deutsche Verlags-Anstalt, Stuttgart, 1952.

${ }^{59}$ See C. Klütsch, 'Information Aesthetics and the Stuttgart School', in H. B. Higgins \& D. Kahn (eds), Early Computing and the Foundations of the Digital Arts, University of California, Berkeley, 2012, p. 68.

${ }^{60}$ Ibid., p. 65 . Both Bense and Moles were also actively involved in writing for the journal run out of Zagreb, Bit, along with Matko Meštrović, author of 'design and environment', see M. Meštrović, 'Design and Environment (Dizajn I okolina)', (1980), Journal of Design History, Special Issue: Environmental Histories of Design, vol. 30 , no. 2,2017 , pp. $216-230$.

${ }^{61}$ Ulm $14 / 15 / 16,1965$, p. 87 . On the influence of Ulm on the history of design and computing (broadly understood), see I. C. Neves, J. Rocha and J. Duarte, 
'Computational Design Research in Architecture: The Legacy of the Hochschule für Gestaltung, Ulm', International Journal of Architectural Computing, issue 1, vol. 12, pp. 1-25.

${ }^{62}$ A. Moles, Information Theory and Esthetic Perception, J. E. Cohen (trans.), University of Illinois Press, Urbana \& London, 1966.

${ }^{63}$ A. Moles, 'théorie de l'information', Bit International, vol. 1, 'The Theory of Informations [sic] and the New Aesthetics', 1968, p. 19.

${ }^{64}$ Moles, Information Theory, op. cit., p. 124.

${ }^{65}$ Moles, Ibid., p. 130.

${ }^{66}$ Ibid., p. 131.

${ }^{67}$ Ibid., p. 165.

${ }^{68}$ A. Moles, 'Products: Their Functional and Structural Complexity', Ulm 6, 1962, p. 7.

${ }^{69}$ Ibid., p. 9.

${ }^{70}$ Ibid.

${ }^{71}$ Ibid., p. 6.

${ }^{72}$ W. S. Huff, ‘An Argument for Basic Design', in M. Krampen (ed), Design and Planning, Hastings House, New York, 1965, p. 65.

${ }^{73}$ See, out of many such examples, M. Krampen, 'Survey of Current Work on the Semiology of Objects', and 'Survey of Current Work in Semiology of Architecture' in S. Chatman, U. Eco \& J-M. Klinkenberg (eds), A Semiotic Landscape, Proceedings of the First International Association for Semiotic Studies, Milan, June 1974, Mouton Publishers, The Hague, 1979, pp. 158-168; 169-194. In both surveys Krampen reviews the work of Ulm teachers Bense, Maldonado and Moles.

${ }^{74}$ For an overview of Fechner's empiricism, see J. Hetrick, 'Aisthesis in Radical Empiricism: Gustav Fechner's Psychophysics and Experimental Aesthetics',

Proceedings for the European Society of Aesthetics, vol. 3, 2011, pp. 139-153.

Fechner is discussed by Maldonado and Bonsiepe in Ulm 10/11, 1964, pp. 21-24.

${ }^{75}$ M. Krampen, 'Experimental Aesthetics', in Design and Planning, op. cit., p. 35.

${ }^{76}$ See P. Betts, The Authority of Everyday Objects: A Cultural History of West

German Industrial Design, University of California Press, Berkeley, 2004, p. 173.

${ }^{77}$ Krampen, 'Experimental Aesthetics', op. cit., p. 35.

${ }^{78}$ Ibid.

${ }^{79}$ Ibid., p. 37.

${ }^{80}$ American psychologist Osgood's early, influential texts were, Method and Theory in Experimental Psychology, Oxford University Press, Oxford, 1956, and C. E. Osgood, G. Suci \& P. Tannenbaum, The Measurement of Meaning, University of Illinois Press, Urbana, 1957.

${ }^{81}$ Krampen \& Hörmann (eds), op. cit., pp. 77-93. Krippendorff, op. cit., p. 311, follows roughly the same partitioning: 'Whereas Bill's designer was to find a new aesthetic unity between contemporary culture and forms of mass produced artifacts without catering to commercialism or relying on sentimental kitsch, Maldonado's designer was to be equipped with the instruments of science in order to coordinate decision making from the centers of industry. Under the influence of Rittel, the conception shifted to a designer who would be able to handle heuristic planning and design methods, and work as equals in product or strategy teams'.

82 This is the name of a radio documentary on Ulm in the late 1950s conducted by Faculty member Bernhard Rübenach, which became B. Rübenach, Der rechte Winkel von Ulm - Ein Bericht über die Hochschule für Gestaltung 1958/59, Georg Büchner, Darmstadt, 1987. In the early years of the HfG, this passion for clarity and indeed 
elegance was played out in an almost monastic manner, as Heiner Jacob recounts, 'Everyone adapted the radical lower-case-only style of writing, which the Bauhaus had propagated previously. All the students wore clothes of a simple, straight cut, preferably in black or grey - colour was thought frivolous. If you had been a painter previously, you stopped painting - it was considered unbecoming for a functionalist. Music was acceptable only if it had the mathematical clarity of J. S. Bach or the syncopated lucidity of the Modern Jazz Quartet'. H. Jacob, op. cit., p. 226. 